The Geneva Papers on Risk and Insurance, 16 (No. 59, April 1991), 207-235

\title{
Measuring the Output of Life Assurance Companies*
}

\author{
by C. D. O'Brien, M.A. F.I.A.
}

\section{Introduction}

Purpose

1.1. This paper arises from asking the question what do life assurance companies produce? Measuring output is often simpler for a manufacturing firm than for a company in the service sector, where the intangible nature of the product may cause a number of difficulties. In life assurance these problems may be especially severe. If, however, a life office is to be effective in managing its operations then a clearer idea of its output may be of considerable practical assistance.

1.2. The answer about life assurance output is also important from a wider economic viewpoint. We see resources of labour and capital in the industry and may ask what is the nature of the return which these factors achieve. Life assurance companies play an important part in the economy, but an analysis of output may suggest how significant this role is.

Plan

1.3. We may view the output of a life assurance firm in a number of ways. It can be considered as the outcome of its employing resources, which are remunerated accordingly: this approach, similar to the "income" measure of national income accounting is considered in Part 2 of this paper. Correspondingly we can consider consumers' expenditure as being used to purchase life assurance output, as discussed in Part 3. Then this links in with a more practical view of the activities of companies as being their output, reviewed in Part 4 . These ideas are then applied to some issues of economics and management in Part 5, and there is a concluding summary in Part 6.

\section{The income approach}

2.1. The nature of the output of a life assurance firm may appear puzzling. From a practical viewpoint perhaps the firm's output is the policies it issues, comparable to a car manufacturer counting the number of vehicles it produces. This seems simplistic, for one policy may be quite unlike another. A policy with a small sum assured is different from one which is large, term assurance and endowment business are not the same in nature, while it may dated.

* Presented to the Staple Inn Actuarial Socicty, 5th December 1989, with statistical information up 
be inappropriate to consider life and pensions contracts together. Of course the problem of a firm producing outputs which are not all identical is common in many industries and there needs to be a measure of output which overcomes the difficulties of heterogencity. In life assurance it is quite clear that simply using numbers of policics is unsatisfactory, and another approach is nceded.

2.2. A number of investigations have uscd a varicty of mcasurcs of output in life assurance. This has often been considered in studies of economies of scale, rclating a company's costs to its output. Burgess \& Walker (1962) regard numbers of policies in force as a simple output measure, and it was also policies which Knight (1964) $\mathrm{cmphasiscd}$ in his work on productivity. Studies such as Johnston \& Murphy (1957), Colenutt (1977b) and Praetz (1981, 1983,1984 ) have focussed on total premiun incomc as the firm's output. Houston \& Simon (1970) use premiums paid as a proxy for output but with somc reference to the mix of products varying bctween companies. Franklin \& Woodhead (1980) discuss many of the problems involved and use a number of premium measures in their study. Diacon (1981) uses several different measures: numbers of new policics, new business sum assured, new premiums or in force premiums. Minto (1989) addresses the issue of output measurement more specifically and considers different types of indicator; and also refers to the value of death benefits paid as a relevant measure.

2.3. It is useful to consider the output question in the light of the principles of national income accounting. The firm applies its resources of labour and capital to produce output, from the sale of which the labour and capital are then remunerated. We can therefore view the value of output as being the sum of wages (the reward to labour) and profits (the reward to capital). In calculating national income all the relevant incomes will be either wages or profits; therefore, in assessing the output of an individual company we can merely sum the wages of its employees and profits for its shareholders. Such is obviously a simplification, but this can now be considered further.

2.4. The principle of using wages plus profits as an output measure is that this is a representation of economic activity: production derives from an economic process, which involves the payment of compensation to the factors of labour and capital involved. If the number of employees is higher, and correspondingly activity in the firm is higher then the additional output will be reflected in the increased total of wages paid. Or say additional capital is brought in, permits a higher level of production, the extra capital being compensated by the increased profits arising. In such terms one can see the rationale for the "incomc" approach.

2.5. A life assurance firm can therefore calculatc its output as its income defined as the sum of wages and profits. "Wages" as a term is used as cconomic shorthand for the remuneration of labour, or employment incomc, notwithstanding the fact that most employees in a lifc office will be salaried. Wages would include both wages and salarics and in addition items such as overtime, productivity and profit-sharing bonuses, and cash payments for achieving sales targets. However, it is appropriate to include not only wages (inclusive of salaries etc.) but also the valuc of any relevant fringe benefits which would typically bc significant. These could include employers' contributions to pension, life assurance and sickness schemes, the value of housc purchase subsidies and the bencfit of chcap lunches. Employers' national insurance contributions may be included: while these are not distributable wages they are of a similar nature in terms of the remuneration of labour resources. The mcasurement of employment income is discussed in Ccntral Statistical Office (1985) although the national 
income accounting practice which it describes deliberately uses approximations such as ignoring travel concessions as a benefit in kind because of inadequate data: but a firm with relevant information on this could of course incorporate it.

2.6. One recent trend in somc life assurance companies is the development of direct sales forces where the salesmen and saleswomen are self-cmployed. Their rewards are typically commission, plus bonuses for recruiting other salesmen, selling a certain number of policies, etc. However note the implication that as thesc are not direct employees of the life assurance company their remuneration would not be counted as part of the firm's output. They are contributing instead to the output of the self-employed scctor. However, insofar as they affect the life office's profits or wage bill there is an impact on the insurer's output.

2.7. Where the income of the self-employed is divided between various industries, then the direct salespersons' income is attributed to the life assurance sector. The total output of the life assurance industry would therefore incorporate wages (of employees), profits (of companies) and the income of the self-employed in life assurance.

2.8. It is the use of profits in the output calculation which is more suspect. First, it should be said that we are considering the gross trading profits of the company. We are not here thinking of profits in the sense that policies may be "with profits", i. e. part of the actuarially calculated surplus being allocated to policyholders. Rather it is the profits accruing to shareholders which are relevant. Interest on shareholders' funds is excluded as not being trading profit, although there can be difficulties in identifying what such interest is which should be disregarded. The figure used is also gross in the sense of being before tax on profits.

2.9. In this sense the profits are the reward to shareholders for the value contributed by the provision of capital resources. However, using profits as declared in the company's returns will depend on the particular accounting and actuarial conventions used. As life assurance is long-term business reserves are set up to provide for liabilities on policies which may or will become claims in the future. The determination of reserves and profits has been the subject of much discussion in the actuarial literature. We can, however, refer to Smart (1977), who defined profit during any period as the excess of income over outgo, where outgo includes the necessary increase in valuation reserves. Now it may be that the regulations on reserve requirements, or the company's established practice on this, err on the side of safety. Given such constraints it follows that there is an impact on current profits. Since there then may be limits on the monies that can be paid to shareholders these constraints are relevant as they affect the return on capital. However, a company preparing output figurcs may feel it appropriate to re-calculate profits on a diffcrent basis relevant to the particular purpose in the hand.

2.10. A wider discussion would acknowledge that actions taken in one year may be reflected in future rather than present profits and this is important in managing the company's operations. Corporatc objectives would be wider than current year profits: they may relate to the return in tcrms of the dividend actually paid to shareholders plus the increase in the appraisal value of the life office. Assessing such values has been discussed in papers by, for example, Burrows \& Whitehcad (1987) and there arc a number of areas continuing to be debated, such as the economic and actuarial assumptions used and the weight to be given to goodwill. The point to cmphasisc is that as life assurance is long-term business, a ycar's profits as conventionally mcasurcd may not be an adequate guide to the profitability of operations. 
2.11. The above has shown that the output of the year's activities may be reflected in

(i) wages (etc.) plus

(ii) profits

This acknowledges the use of the company's resources in economic activity. However, this measure is in current rather than constant prices and so is not an index of real output: we would therefore need to apply a price index to deflate the above output measure to constant prices. This and further points are considered below.

\section{The expenditure approach}

3.1. If we have identified a company's output then wc ought also to be able to see this as being purchased by consumers. Since national income is, in aggregate, the sum of consumption and saving we should be able to recognise what part of consumers' expenditure is spent on life assurance.

3.2. A simplistic approach would treat expenditure on life assurance as being the premiums paid to the life offices. We have seen that there are surveys where this can be thought of as an indication of the company's output. However, this would be seriously misleading.

3.3. Again a comparison with national income accounting is valuable. For in aggregating individual incomes to form the national total we exclude "transfer payments". These payments, such as state pensions, are transfers which do not reflect the outcome of economic activity and must be excluded to avoid double-counting. In the same way we can see that much of life assurance premiums are essentially transfer payments. They are a means of transferring monies from one point in time to another, dependent on contingencies such as death, sickness or survival. Clearly the transfers are not merely over time but also between people: depending on the timing of the events such as death there are gainers and losers. But overall, much of the total of life assurance premiums which a company receives will effectively be transfer payments within the body of policyholders.

3.4. We then need to isolate what part of the premiums received is not a transfer payment but a reflection of economic activity. Clearly one part of the answer relates to the company's expenses: these are not transfers but reflect the cost of the actual activities undertaken. These expenses can in fact be divided into "wages", in the way described in para. 2.5. and "others". The wages are then the expense in relation to the services of (directly employed) labour; the other expenses will be the cost of purchases of intermediate goods and services. These will include not only items such furniture, rates and auditing fees but also commission to agents including self-employed salespersons (the latter as referred to in para. 2.6.). Commission is the expense of the services provided by agents and is part of the agent's output rather than that of the insurer. Similarly reassurance is an activity of the company actually taking the risk. The same principle applies to other intermediate goods and services, i.e. they are the output of the supplier whose labour and capital resources are used to produce them.

3.5. We can here distinguish between net output and gross output. It is net output which we have up to now considered, being described in Part 2 as the sum of wages and profits, reflecting activities of the company's resources. If however we add in the cost of intermediate goods and services purchased the result is gross output, which is equivalent to turnover. This therefore reflects the company's activities more widely but encompasses the operations relating to resources not directly in the life office's control. 
3.6. A further part of the premium paid which is not a transfer is the profit to the shareholder. This may be taken as the profits as shown in the company's returns. However, it is recalled that this will depend on the particular actuarial and accounting procedures employed.

3.7. Note also that part of premiums may be used to pay any indirect taxes: we can consider stamp duty in this category. If included in the output measure then this is equivalent to the national income being measured at market prices; if not, then at factor cost. Either may be appropriate depending on the circumstances.

3.8. We can now view output as being that service for which the policyholder has been prepared to pay. The insurance output has a value and it is this which the policyholder is prepared to forgo in contrast to the remainder of his premium being treated as a transfer payment. Different policyholders may regard these outputs differently. For example, a new policyholder would (if only notionally) envisage a large deduction from his first premium in respect of the cost of selling and setting up records of the policy. A policyholder paying a renewal premium would expect only a small deduction relating to the lower servicing at this stage. A customer taking out certain types of pension policy may acknowledge the greater element of his premium to provide the documentation required.

3.9. The argument above may appear rather theoretical. There are financial institutions such as building societies which offer savers a return on their money apparently without a direct charge for costs. Customers may therefore expect life assurance premiums to be "fully" invested; hence, for example, complaints about surrender values in the early years of an endowment policy being less than the premium paid. However, obviously these costs are incurred, and customers effect policies and receive claim payments. In economic terms output is not merely what a company produces but what its customers are willing to pay for. There have been arguments that policyholders do not understand or appreciate these costs; hence the discussions on regulation regarding disclosure of charges or costs. Here one is viewing the policyholders as accepting the costs, and the services as being the insurers' output.

3.10. We must also acknowledge that policyholders pay to have the policy sold to them, i. e. they accept the acquisition expenses as paid by the insurance company. Furthermore, a policyholder pays for the costs of the sales organisation in failing to sell, i. e. in approaching individuals who do not actually effect a policy. This principle is evidently true in the context of buying goods in a department store, and it is being taken as being no less true in life assurance.

3.11. The recognition of the importance of costs appears in Marshall's (1974a and 1974b) analysis of insurance. One view of the industry stresses the reserves built up to meet contingencies. Alternatively one can regard insurance as trade in contingent claims, which might then be arranged on a mutual basis with no role for an insurance industry as such. However, it was argued that the existence of transaction costs means that firms can arrange this trade more efficiently than otherwise, and this arranging is their output.

3.12. This line of argument ties in with considering (net) output as value added in economic terms. If we envisage the insurer as purchasing intermediate goods and services, and receiving the transfer element of premiums, its true contribution to economic activity is then the value specifically generated by using its labour and capital resources to provide services for which the customer is willing to pay. This is then the additional value created by the life assurance company. 
3.13. Such an approach may be easier to view after a policy has become a claim rather than at the outset when initially effected. When a policy commences there is unlikely to be any formal agreement as to what part of the premium is an output rather than transfer element. There may, however, have been an assumption on this in any illustrations or quotations given to the policyholder though without any commitment. If the office's experience on expenses is such that these are higher than anticipated then the transfer element may be reduced and the output element accordingly increased. We are then assuming that the policyholder accepts this situation, i. e. accepts the reduced claim payment because the cost of providing the insurance company's service is high.

3.14. We should also consider the position if the company's experience on say interest, mortality or expenses is adverse and the life office makes a loss overall rather than a profit. Its output will be less than the wage costs and may conceivably be negative. What this reflects is that policyholders have not paid sufficiently high premiums to cover the expenses and the transfer payments. Now it may be that they would have been willing to pay higher premiums, particularly if they had had better knowledge of the possible adverse experience. There is an argument that in splitting premiums into the transfer element and "other", it is appropriate to use an average experience on mortality, etc. for the transfer, thus smoothing out variations and producing a more even output result. However, this involves discretion in determining the "normal" level of transfers and is undesirable. It is better to accept what the policyholders in fact paid (rather than would have been prepared to pay) although then bearing in mind that short-term variations in output may be open to a number of interpretations.

3.15. We can therefore see premiums being analysed as comprising:

(i) payments to employees

(ii) payments to shareholders

(iii) payments to providers of intermediate goods and services

(iv) indirect taxes

(v) transfer payments

Then net output $=($ i $)+($ ii $)$; gross output $=(\mathrm{i})+($ ii) $+($ iii $)$; for market price value rather than factor cost : add (iv).

3.16. We can therefore see that the outcome is consistent with the income approach of Part 2. Life assurance premiums are largely transfer payments but they include parts relating to the services of labour and capital which are remunerated for the functions they perform. It is these functions which the policyholders pay for directly and it is this part of expenditure which corresponds to the life assurance company's output. This approach again gives us an answer in terms of current prices; if we are to convert to constant prices then we must examine more closely the output functions provided by the life office.

\section{The output analysis}

4.1. If we consider the employees in a life assurance company and ask what service they provide then for many it is an administrative service. This is very necessary to be able to deal with enquiries from policyholders and fulfill the company's obligations to them. It may also be said that these administration services include some of a technical nature: say actuarial calculations or the drafting of pension scheme documents. 
4.2. We must also consider the function of investing monies. This investment function is obviously a crucial service undertaken by the life office and is an essential element of many types of policy.

4.3. In addition, the selling element is clearly very important. Life assurance, it is commonly argued, is sold rather than bought and the customer pays for the cost of having the policy sold to him, as a part of the premium. The expenses of acquiring new business are typically a large proportion of a company's costs.

4.4. It may be argued that the "handling" functions of administration, selling and investment are provided by the company's employees. However, where capital is spent on say equipment to improve administration then this may contribute to an increase in efficiency and higher shareholders' profit so implying that the administrative - and also investment and selling - services can reflect the contribution of capital as well as labour. Indeed, the strain of writing new business is often such as to require substantial shareholders' capital in order to make possible the servicing of new policies.

4.5. However, the role of shareholders' capital can be substantially greater than this. By providing a reserve fund which would be available to policyholders in adverse circumstances it enables guarantees to be given and options to be made available which otherwise would not have been possible. The shareholders' backing may also mean the office can take greater risks in investment or in assessing lives' prospective mortality. We can summarise these overall as an "insurance" service. While typically we can consider such a service as provided by capital this may be misleading if we forget that also employees are involved in designing and administering such guarantees, etc.

4.6. To date there has been no specific mention of mutual companies. It is sometimes said that mutual companies must have better premium rates than proprietary offices as the latter need a loading on premiums to pay for the profits. This view is simplistic. A life office's need for capital is discussed in Earle's (1972) paper which shows how the requirements depend on a number of factors and therefore illustrates how capital enables a higher level of activity or improved performance in the company. We can therefore argue that shareholders' capital enables a company to do better than if it had no such capital by, for example, arranging more efficient administration or offering greater guarantees. Where this results in higher premium rates it may be because additional services are being offered for which the customer is prepared to pay: one would not expect the policyholder to accept inferior terms as if shareholders' capital performed no service at all. The argument is of course dependent on there being an appropriately competitive market.

4.7. It should also be noted that the transfer payments to which we have referred may be between generations of policyholders. Part of the essence of conventional with profits business is that reversionary bonus rates are not subject to violent changes and one cohort of policyholders may subsidise or be subsidised by another. Where mutual offices have built up large reserves in excess of the value of liabilities this is known as the estate, although in economic terms this can still be considered as funds to which current and fut ure policyholders have rights. There may also be a large estate in proprietary offices which have in the past written large volumes of conventional business, in which shareholders and current and future policyholders would have an interest.

4.8. It would be wrong to think that mutual insurers provide no "insurance" function because they have no share capital: they obviously issue contracts which involve risks and 
offer options and guarantees. These are, however, supported by the (current and past) policyholders. Those customers with policies containing a high level of guarantees should pay an appropriate premium to reflect this; the benefit of this will (depending on actual experience) pass to other policyholders who are taking risks from the fact that highguarantec business is in force. The payments for guarantees remain transfer payments within the overall account of policyholders. However, the value of the guarantees will depend on the capabilities of the policyholder funds: it is a role of share capital to make possible more of this insurance function.

4.9. We can therefore argue that the calculation of wages plus shareholders' profits understates the importance (in some sense) of life assurance. Essentially, we also have trading between the policyholders which in national income accounting terms is ignored as being a transaction that is "social" rather than "economic". This trading may be on terms such that some policyholders accept claim values which are less than the relevant reserves and so a substantial fund is built up. When this permits greater insurance guarantees than otherwise for future generations of policyholders it is the basis for what we may regard as further trading between policyholders, including between different generations. However, it is not clear how we can assess the value of this mutual trading; certainly we do not observe prices or incomes directly relevant to those "notional" transactions. The position is more complex still in proprietary companies where guarantees are backed by both shareholder and policyholder funds. We can therefore be clear that the output as we are measuring it does not represent fully the operations of life assurance. However, what it does represent is the services provided by the labour and shareholders' capital resources of life offices.

4.10. We have seen that the insurance company output relates to its services of selling, administration, investment and "insurance". These will relate to the policies sold as reflecting the business transacted. We can refer to Gershuny \& Miles' (1983) analysis which emphasises human needs in terms of the services which individuals want, and the way in which goods enable these service needs to be met. It is therefore useful to think of life assurance customers' needs for insurance, administration, etc. rather than the actual contracts which are issued. Although the policies may represent the output, the essence of life assurance production is the functions undertaken to provide services to policyholders.

4.11. Let us take the gross output measure discussed in para. 3.5. of expenses and profits and say an office's calculations show that its output has increased. But if the higher output arises from an increased level of expenses, how do we know that this is not an indication of greater inefficiency rather than increased output?

4.12. It must be recognised that the output measurements considered to date have been in current price terms. The expenditure approach indicates what part of premiums are being forgone by policyholders (as opposed to being regarded as transfers) to pay for certain "functions" and the expense plus profits measure is, in current prices, what is spent on these activities. But we have identified these true activities as, for example, administrative - say the collection of renewal premiuns. The relevant expenses may be thought of as a quantity (the number of policies renewed) multiplied by a price at which that activity is performed. Similarly the total expenses could be considered as an aggregate for all the individual functions, of a quantity and a price.

4.13. By looking at these individual activities we can produce more meaningful results than using merely the total of policies. We could say at a "corporate" level that output 
equal total expenses plus profits, of $£ 5 \mathrm{~m}$, amounting to activities worth $£ 50$ on each of 100,000 policies. There is then a price of insurance output of $£ 50$ per policy, and a quantity of 100,000 . However, policies will be dissimilar in terms of the functions performed: the problem of aggregating different outputs. We therefore need to identify more precisely the functions being performed, moving away from generalised activities to the more basic units of service output. Then it should be possible to assess the price of each such service supplied.

4.14. In looking for these basic service units we would aim for them to be homogeneous activities, i. e. not subject to large variations in "quality". An example would be to say that the servicing of a new policy is greater than that for an existing policy as the former involves much more selling and administration activity. We may also wish to distinguish between life and (certain) pension contracts if say the latter involves arranging documentation with the Inland Revenue. We had therefore started with the generalised activity in relation to all policies: this was not a homogeneous measure. If there were an increasing proportion of pension contracts then using the generalised measure would understate the true output increase because on average there was more activity per (overall) policy. We might express this as an improvement in quality, i. e. more being undertaken for a given unit of the generalised activity - similar to a switch from paperback books to hardbacks so that book production would not adequately express the activities being undertaken. However, it is more useful to specify what we may think of as the basic service units, each of which is homogeneous (say paperbacks and hardbacks; life and pension policies) so that we can count each as a measure in itself, less subject to variations in quality, and weight them to give an overall total.

4.15. When identifying units of output then it is at the very general level that one has to be careful about assessing quality changes. If the function is defined merely as "dealing with a policy" then this obviously leaves much scope for judgments on how the quality of this service may alter from time to time. Hence the need for well-defined more detailed indicators from which an overall output index can be built.

4.16. In seeking the basic service units - the "building blocks" in a total measure - we can learn from the studies undertaken of insurance company expenses. For example, Colenutt (1977 a) examines expenses in relation to a number of parameters including single premiums, immediate annuity considerations and immediate annuities in force, new yearly business, schemes business, a lapse ratio, average policy size and proportion of overseas business. This analysis also included a number of dummy variables to assess the impact of varying the type of assurer, e. g. mutual or proprietary. Finsinger, Hammond and Tapp (1985) include a number of parameters, such as the amount of business which is unit-linked. Luffrum, O'Leary and Shedden (1986) describe a regular investigation into life office expenses which uses companies' internal expense allocations to determine typical expenses in relation to a number of types of policy, with a distinction between new and existing policies. Where particular variables are important in affecting an office's expenses this may imply they are significant indicators of what are the company's activities; we can therefore weight the activities according to relative expense to produce an index of total output as shown by Elven (1964).

4.17. A study which very clearly relates expenses to output is the Canadian analysis of Hirshhorn and Geehan (1977). They identify that insurance company output reflects the activities undertaken and, consistent with national accounting procedure, treat what is the 
major part of premiums as directed to covering disbursements to the policyholder. It is also recognised that in producing an overall measure one of the major difficulties is heterogeneity and hence there are several "building blocks" in their overall output measure. There was separate consideration of the different types of insurance policy (e. g. temporary and other, single premium and deferred annuities, group schemes, total disability waiver of premium, disability insurance and vested annuities); a distinction between first and subsequent years of a policy life; reference made to numbers of policies, benefits and premiums, and different types of asset invested. In this way it is easier to assume that the quality of output at the building block level remains reasonably constant, and given that homogeneity at "local" level it is meaningful to make the aggregation to give an overall total.

4.18. From the several individual parts of the Hirshhorn-Geehan output calculation one needs to decide the several weights needed. The solution uses the Canadian industry expense analysis which suggests how expenses are in practice related to the various types of policy, etc. These expenses reflect the significance of the actual company operations and are therefore used as weights although a number of adjustments need to be made to the formulae. It should be noted that the resulting output measure is of gross rather than net output. It also excluded consideration of "intermediate activities" - terminations, lapses, benefit payments - though this seems inappropriate since the policyholder still pays for the administrative service in these transactions. The authors also referred to shareholder profits as being small in Canada in relation to company operating expenses and no explicit allowance was made for these in the output total.

4.19. A company designing its own output measure needs to determine what its "building blocks" are to be, and would find it useful to examine its own expense analysis first. For example, it may find that its expenses are greater for joint-life than for single life policies; it could then design its output measure accordingly by giving more weight to the joint-life policies to reflect the greater servicing activity for them.

4.20. The following suggestions are made as to the building blocks for an output measure, and what parts of the business may need to be distinguished:

(i) to indicate selling activity one needs to count the number of new policies sold and say distinguish those arising automatically if the policyholder in an earlier year requested incremental policies.

(ii) administration servicing may depend on the length of time a policy has been in force, and hence a duration analysis of policies is necded (new policies need considerable administrative processing; in the next two years say there may be more policyholder encuiries than in subsequent years; the distribution of claim payments has a different impact).

(iii) selling and administration expenses may depend on the selling channel.

(iv) large policies may require more selling effort and subsequent administration; assessing "large" may need reference to premiums, benefits and term of policy.

(v) the type of policy may affect the selling and administration service, c.g. joint life policies requiring to be sold to two individuals rather than one and subsequently subject to administrative procedures in the event of divoree; if an insurer offers a mortgage loan with certain endowment policies this will require greater service and expense; 
unit-linked policies may have separate procedurcs from conventional and hence involve different expenses; certain pension policies may require the insurer to have documentation completed and then approved by the Inland Revenue.

(vi) administration servicing may depend on the way in which premiums are collected and also the frequency of payment

(vii) the investment service will relate to reserves and hence there would be a distinction betwecn policies with low and high premiums and according to product type as to whether a substantial reserve was built up.

4.21. In the above way it is possible to sct out the "basic service units", with examples being

- the setting up of records of new individual pension policies

- acquisition of new unit-linked policies through brokers

- the administration of lifc policics which have been in force over 5 ycars

and record the numerical value of an appropriate indicator, e.g. the number of new individual pension policies. The detail required for the basic service units will depend on the use to be made of the resulting output index. If many units are identified then the construction of the index will be complex and require a more extensive data collection system; but it avoids the problems of heterogeneity and changing quality in the same generalised activities.

4.22. It is less easy to think of separate building blocks to represent the "insurance" service from shareholders' capital. Such functions may include :

- the guaranteeing of benefits on death

- the guaranteeing of a sum assured at maturity under non-profit endowment policies

- the offering of new policies for existing policyholders which could be effected without evidence of health.

However, listing all such functions is difficult, in addition to which establishing the appropriate measure may be a problem. One could use say:

- the death strain at risk

- the guaranteed sum assured (or excess over reserves), in total, for non-profit endowment policies

- the maximum sum assured under options for increased bencfits without evidence of health.

However, the insurance "function" is complex and the above could not be regarded as adequate indicators of its valuc.

4.23. Indeed our view of output is morc casily recognised "in arrear" of a policy life, i.e. after we have scen what has been disbursed on claims, expenses and profit, rather than "in advance". An essential difficulty is that each premium will typically not scparate out precisely the transfer element. It is true that this is more nearly the case with unit-linked policies where the proportion of the premium allocated to investment is specified in advance, although some of the expense or mortality deduction may be open to discretion or dependent on actual expericnce. We can also sce from profit-testing models as described in Lee (1985) 
the way in which company management can identify on a year-by-year (or month-bymonth) basis, how premiums are expected to be allocated into various categories. One would check by monitoring whether these results are achieved in practice.

4.24. We may link this analysis with the company's premium bases. If the output analysis finds that servicing in the early years of a policy life is genuinely greater than subsequently this can be reflected in premium bases as more realistic than an assumption of constant or inflation-linked renewal expenses. The premium rates will then recognise the liability for providing these services at certain costs; the output analysis has identified what services are provided, and one can establish monitoring procedures to check that actual experience is in line with assumptions.

4.25. It may be useful at this point to summarise the procedure for calculating the price of the various functions and hence being able to derive an output measure which ignores price changes.

(i) specify the activities (in more or less detail), for example along the lines described in para. 4.21.

(ii) apportion the company's expenses between these activities; it is recognised that the allocation of costs may be a problem, especially for overhead departments and if activities have been defined in detail. Then carry out (iii) to (vii) below in relation to each such activity.

(iii) record the numerical indicator for the activity.

(iv) consider the amount of service provided as being a number of "basic service units", equal to the numerical indicator in (iii) but modified for any change in "quality" as judged appropriate and where this is not taken into account by the numerical indicator.

(v) determine the price as the expenses for this activity, from (ii), divided by the number of basic service units, from (iv).

(vi) we then have, for the function, the expense paid by the policyholders expressed as quantity (no. of basic service units) multiplied by the price of the function.

(vii) in subsequent years repeat the calculation using the new quantity (in basic service units) which if multiplied by the original price of the function will give the value paid for the function in constant-price terms and hence illustrate the increase in real output.

4.26. We can proceed to a practical example but first let us now consider a life office whose expenses have increased, with premiums unchanged, and see how this may be viewed from the output analysis:

(i) if there is no reduction in the "transfer" payments to policyholders; then even if the office appears to be performing more services associated with the increased expense this is of zero value to the policyholders, who demand the previous level of transfers. In this case profits are reduced by the increase in expenses and overall output is unchanged.

In the following cases it is assumed that profits are unchanged and the transfer payments reduced, i.e. in that sense the extra expenses are accepted by the policyholders, although in practice they may have little option but to accept. The essence of output is not merely that it is a service but that it is a service which policyholders are willing to pay for. 
(ii) The functions being performed by the office may be completely unchanged, in which case it is the price of these services which has increased. Output in current prices has increased but in terms of output $=$ quantity $\times$ price it is the price which has risen, and quantity, or real output, is unchanged.

(iii) The functions have changed in terms of an increase in the indicators of generalised activities used (e.g. number of new pension policies) in the output calculations. So in the equation "output $=$ quantity $\times$ price" it is the quantity, i.e. real output which is higher.

(iv) The functions have not changed in terms of the numerical indicators used but there has been an improvement in quality such that the number of basic service units has increased. Therefore the price per basic service unit supplied has not increased and there is a real increase in output.

4.27. From the view of company management it is important to distinguish situations (ii), (iii) and (iv). Situation (ii) may be due to a general increase in costs or may reflect an inefficiency in operation. It is reassuring if (iii) or (iv) applies since this indicates that there is an increase in the functions supplied. (iii) is easy to determine as there is visibly an increase in numbers of new policies, etc. It is (iv) which is problematic since this requires judgment to say that the basic service units per new policy issued (say) have increased.

4.28. We can now consider an output index which is a summation, across several individual functions, of output related to quantity, quality and price. A simple example - at "intermediate" level as opposed to the "corporate" level of para. 4.13-might assume that we analysed activities so as to distinguish between dealing with new and existing business and also between life and pensions policies. The figures in Appendix 1 show how the expenses increase from $£ 3.510 \mathrm{~m}$ in year 1 to $£ 4.445 \mathrm{~m}$ in year 2 , a $26.6 \%$ increase. The company's expense analysis shows how the costs are divided between the four areas, and the number of the units of quantity are known. In year 1 the price of carrying out each unit of the four functions has been determined, i. e. $£ 110$ for dealing with a new life policy, etc. Note that the output is expressed as the services (selling, administration and investment) in relation to the new life policy rather than the new life policy itself; in this way we are focussing on the activities being undertaken.

4.29. It is also seen that we have introduced a "quality indicator", set at 1 for each of the four functions in year 1 . In year 2 , however, we judge that this quality indicator has increased to 1.055 for dealing with new pension and 1.05 for existing life policies. By this we mean that the basic service units relating to the generalised activities of dealing with a new pension or existing life policy have increased by $5.5 \%$ or $5 \%$. Therefore given 8,000 new pension policies the number of basic service units corresponding is not 8,000 but 8,440 .

4.30. In year 2 we can also divide our expenses between the four functions and calculate the cost of the basic service units, e.g. $£ 114.55$ in relation to a new life policy. For new pension policies it is shown that 8,440 basic service units were supplied and the cost of each such unit was 197.87 .

4.31. To establish the increase in (real) output we need to remove the cost increase element from the overall rise in expenses of $26.6 \%$. Therefore if we take the year 2 output in terms of the quantity indicators of generalised activities (i.e. new life policies, etc.), and apply year 1 prices and year 1 quality, we find an output of $£ 4.063 \mathrm{~m}$, or a $15.7 \%$ increase. 
4.32. However, we should also take account of the quality increase in year 2 since this reflects the greater number of basic service units. We therefore calculate year 2 quantities using year 2 quality but at year 1 prices; the result is $\$ 4.187 \mathrm{~m}$, or a $19.3 \%$ increase. This is a more realistic indication of the greater output.

4.33. Obviously there may be a temptation in such an exercise to overstate quality improvements, particularly where it is not clear how the changes in "quality" are valued by policyholders. A check on this may be the implied increase in prices. In the example in Appendix 1 this is $4.445 / 4.187-1=6.2 \%$. If this is significantly different from the change in the general price level then further investigation is warranted. And where the quality improvements appear high it is appropriate to seek more detailed indicators which are more homogeneous and hence less likely to be subject to quality changes: they should reveal the position more objectively. Some examples of quality assessment (in government departments), examining say the timeliness of and accuracy in providing services, are given in Lewis (1986).

4.34. Now consider the position if we had merely said the generalised activity was dealing with (selling, administering and investing in relation to) policies. This "corporate" level analysis would be as in Appendix 2. Here the crucial point to note is that output only appears to increase by $6.6 \%$ to $£ 3.742 \mathrm{~m}$ unless we take into account also a quality improvement of $11.9 \%$ which then gives year 2 output of $£ 4.187 \mathrm{~m}$ at year 1 prices. This partly reflects the fact that in year 2 a higher proportion of policies which are dealt with are new and therefore subject to more servicing, hence why the $11.9 \%$ figure is so large. However, without completing the analysis in the detail of Appendix 1 it would have been difficult to derive this $11.9 \%$ result; the heterogeneous activity of "dealing with policies" is not adequate in those circumstances.

4.35. We could also proceed in the opposite direction and analyse in greater detail than in Appendix 1. This involves identifying activities more narrowly so that they are (more nearly) homogeneous. If we consider the activity of dealing with existing life policies we can see that this covers a wide range of activities. Appendix 1 indicates this involves supplying (in year 1) a service costing $£ 10$ to each of 80,000 policies. But in practice the expenses would not have been $£ 10$ for each policyholder; they may have been largely the result of dealing with specific requests from certain clients. Thus the expenses would be much less than $\$ 10$ for most policies, and considerably higher for the minority enquirers. If the proportion of policies which are subject to specific enquiry increases then "handling an existing life policy" is not a homogeneous function and one needs to analyse the services in greater detail.

4.36. Appendix 3 therefore sets out how one might break down the generalised activity of dealing with existing life policies. In such more detailed units one is less likely to have quality increases though this was identified in relation to the sending of statements to policyholders. Overall the increase in basic service units was $8.94 \%$. This is the same as Appendix 1 shows for existing life policies.

4.37. It is noted that what we treat as quality changes depends on the level of aggregation being used. At the corporate level in Appendix 2 quality has to encompass everything that cannot be captured in the one measure recorded.

4.38. The above methodology may also be applied to individual sections or branches of a life company. There may appear to be fewer problems of heterogeneous output if say a 
section is merely dealing in one function, e.g. calculating surrender values. Let us consider this at three levels though.

(i) At a very broad level the section may consider its function as providing a service in relation to say life policies more than two years in duration; its output indicator may be the number of such policies in force; the section's expenses of $£ 35,000$ are this output (assumed 70,000) multiplied by the price per policy at which this service is supplied (£ 0.50$)$.

(ii) However, it may be recognised that the section's activity relates more closely to dealing with the enquiries it receives from policyholders and may measure its output in terms of the number of such dealt with (say 4,000$)$ multiplied by the price for dealing with each such enquiry (£ 8.75). This may be a more appropriate analysis than in (i) since the proportion of policies resulting in enquiries to the section may not be constant, i.e. the scrvice related to total policies is not homogeneous.

(iii) At a more detailed level, however, the activity of dealing with an enquiry may itself be heterogeneous. Say it is more time-consuming to reply direct to a customer from an enquiry in contrast to where the reply is to a broker. We may then identify these two functions as dealing with customers $(3,000$ at $£ 10)$ and with brokers $(1,000$ at $£ 5)$, total section expenses being $£ 35,000$. If the relative proportions of the two activities (policyholders; brokers) are constant, then we could then consider "handling an enquiry received" as effectively homogeneous - but if they change then the measure in (ii) may mislead. Such a problem may be trivial at company-wide level but if output and productivity measures are important elements in judging a section's performance then changes in their detailed activities would need to be taken into account.

4.39. It should be clear from the above that we have a system for output calculations at various levels. Starting from narrowly-defined reasonably homogeneous activities one can build up an aggregate measure that illustrates the changes in activities taking place.

4.40. Note that the index number problem has appeared here. In Appendix 1 there is a choice of using year 1 prices or year 2 prices in calculating the constant-price output measure. Alternatively a "standard" set of prices may be used throughout to give a consistent measure. This point has been discussed by a number of writers on output and productivity measurement and will not be considered further in this paper.

4.41. Expenses incorporate purchases of intermediate goods and services. In assessing output changes in some industries it is usual to use gross output as a proxy for net output: this can be convenient and a reasonable assumption. We should, however, be aware of any changes arising from say outside consultants, or self-employed salespersons undertaking activities rather than employees. Trends in the life assurance industry may have reduced the ratio of net to gross output.

4.42. One possibility is to start by calculating gross output (i.e. using all expenses) in constant-price terms. Then one deducts the value of intermediate purchases adjusted to constant prices using an appropriate price index (and indicator of quality change) which is not necessarily the same as that used for the gross life assurance output. However, this "double deflation" exercise would be difficult to use in practice.

4.43. An alternative is to ignore the expenses of intermediate goods and services in the calculation of what is then the net life assurance output. We then arrive at the price, for 
each function, of the services provided by the life office's employees in relation to each activity (the quality indicator should strictly be assessed in relation only to those services rather than the whole as seen by the policyholder).

4.44. We have previously referred to policy size as relevant in that large policies are not the same as small. In some respects the handling costs may be identical but certainly acquisition and investment costs will vary according to size. When assessing the functions per policy we can calculate a "quality" increase to reflect the change in size taking account of various parameters which may be relevant indicators of size, e.g. premiums, length of policy term, sum assured or annuity (this can be established through the company's expense analysis). We can then incorporate an assumption that the "quality" only increases to the extent that the average size rises more quickly than general inflation. It may seem more logical to use these size effects to modify the quantity indicators directly rather than by a quality adjustment, though this is not easy if there are a number of dimensions of size. An example of some calculations is given in Appendix 4. Another possible approach is that used in the assessment of industry output in Appendix 6, referred to in para. 5.14.

4.45. To date we have considered output related to the company's expenses but for proprietary companies we must also take into account the gross trading profits for shareholders. From the policyholder's view such profits are very like an expense, being a payment for services provided. In relation to the function of selling, administering and investing for new life policies, if the expense per policy is $£ 110$ and the shareholder's profit per policy is $£ 20$ then the total payment from the policyholder is $£ 130$. This is therefore the true price of the function.

4.46. The expense analysis could therefore be repeated but incorporating profits in order to derive the output measure correctly. However it is unlikely to be possible to do this in detail as profits would not be calculated in relation to each of the narrowly-defined functions described above. The accuracy of available results may depend on the company's organisation and its monitoring system of financial control.

4.47. There is, however, a further difficulty. One of the functions of shareholders' capital is to enable guarantees and options to be granted, for which the policyholder correspondingly pays. We therefore need to separate the profits in relation to this function which can be included as an additional service in the analysis of Appendix 1. There is, of course, no observable price for this service since the premium paid relates to the combination of services and transfer elements.

4.48. In establishing the services of the insurance functions this would be on the lines of:

(i) identifying activities such as guaranteeing a sum assured on death or maturity, or the offering of options

(ii) using indicators such as the death strain at risk (see para. 4.22.).

One may be able to design more sophisticated measures though one is still limited by the problems involved in the actuarial valuation of options and guarantees, and the measures do not appear very satisfactory.

4.49. A further difficulty is to consider potential changes in the "quality" of the service of offering options and guarantees. Say for example the value of the life fund investments declines so that the death strain at risk increases. But if there is an unchanged amount of 
shareholders" capital then the "quality" of the guarantee may decline as there is no extra ability to meet the greater strain; indeed if the shareholders' reserves are in assets which have also declined in value then the position is even worse. Similarly, consider the writing of new policies which increases the amount of business in force and again - with unchanged capital - may lower the quality of guarantees.

\subsection{We had wished to}

(i) allocate "insurance" profits between the various insurance functions

(ii) determine an indicator of "quantity" for each such function

(iii) assess a possible quality change for each function to calculate the "basic service units"

(iv) in year 2 thereby decide how the new cost of the function, i. e. insurance profits, can be analysed into a change in quantity (the basic service units) and, residually, into a price change.

So say profits increase, perhaps resulting from additional business, then if the guarantees are then less valuable the decline in "quality" may mean that the basic service units fall, and the increase in profits is therefore an increase in price for the service as opposed to being fully a higher level of output. But assessing all such factors is a very considerable problem.

4.51. We are therefore left with the problem of that part (or all) of profits which cannot be incorporated in the analysis of the selling + administering + investing functions. It is suggested that this may be translated into constant-price output by using a price index which is

(i) the same as that applied overall to the selling + administering + investing functions, or

(ii) general, say the consumers' expenditure deflator.

If we are dealing with (part or all of) profits which are thought to relate to the "handling" functions then (i) would be appropriate. Otherwise there may be little reason to suppose that the price of insurance functions relates similarly to (i) and, subject to adjustment in the light of what information was available, one would use (ii).

\subsection{Appendix 5 puts together these ideas by}

(i) starting with the "intermediate level" activities in Appendix 1

(ii) allocating part of profit to these activities

(iii) calculating a revised price for these activities to incorporate both the wages and profit elements

(iv) the remainder of profits is allocated to the insurance function which is assumed to have a nominal quantity of 1000 in order to derive a price which is then assumed to rise at $5 \%$ as per the consumers' expenditure deflator

(v) calculating year 2 expenses plus profit at year 1 prices and year 2 quality: the total is $£ 5.826 \mathrm{~m}$ which represents a $16.3 \%$ increase in real output over year 1 .

4.53. It may be recalled that the output measures in Parts 2 (the "income" approach) and 3 (the "expenditure" approach) were in current price terms only. Examining the output functions more closely in Part 4 has demonstrated the variety of activities which need to be disaggregated so that the true increases in price and real output can be distinguished. The answers to the output question are consistent, using the three approaches, but it is the activity analysis which enables us to calculate figures at constant prices and hence the changes in real output. 


\section{Applications}

5.1. A full analysis of output on the lincs described above would obviously be expensive to arrange, and given the judgments and approximations nceded, a company would have to decide on the depth of investigation suitable for its purpose. However, the conccpts undcrlying output may themselves be valuable in cconomic and managerial applications.

\section{Financial services taxation}

5.2. The taxation of financial services is often scparate from other industrics. The way in which they handle money means they are not dealing with goods and services in the same way as many firms and one needs care not to adopt tax measures in an inappropriate way. Neverthelcss one expccts financial services industries to bcar their "fair" sharc of the tax burden although consideration of this should encompass all relevant taxes.

5.3. One area of special treatment is the exemption of life assurance from value added tax. There are practical difficultics in applying VAT to financial scrviccs which are not solved by the identification, at company level, of value added as representing the remuneration of labour and capital for the functions supplied. Life assurance cannot be incorporated into mainstream VAT. Taxes of life assurance should, however, recognise the important distinction between the economic activity in the industry and that part of the business which represents transfer payments.

\section{Productivity in life assurance}

5.4. The output analysis which was described can be used as the basis for productivity measurement. Sometimes productivity is used to mcan merely efficicncy in general although here it is used with its economic definition of output per unit of input. In Knight (1964) there are some relatively simple calculations of types of output divided by numbers of employees. The issue has been topical recently in conjunction with studies of the impact of new technology in the industry - see for example Barras and Swann (1983) and Rajan (1985).

5.5. Obviously a productivity index must involve an indicator of inputs. Measuring labour input will involve calculation of the number of employees. Crude figures of staff numbers may require adjustment to reflect changing proportions of part-time staff and alterations to the length of the working week or year. Exactly what amendments are made depends on the purpose in hand. Denison's (1967) analysis of economic growth also considers labour input in terms of changing cducation lcvels of cmployees and other indicators of "quality". We recognise that "one employcc" as a unit of labour input is not homogcneous, hence wc could think of a more basic unit of input, express the number of employees as a number of basic units which takes into account differcnt types of employee, and reflects the supply of labour services.

5.6. In practical terms a life office may calculate its input as numbers of employees, say fulltime equivalents. The productivity measure would then be determined as output divided by input. Then say the company's employment policy changed so that staff were on average more highly-qualified, of a higher "grade". The productivity mcasurc on a "per employee" basis would (prcsumably) show an increase, whcreas "per basic unit of input" would not. Which approach onc takes depends on the purpose for which the results are to bc used.

5.7. Dividing the output total by a measure of labour input gives labour productivity, whereas a more completc index would take account of capital inputs to produce total factor 
productivity. The input measure then has to be a wcightcd avcrage of labour inputs and capital. Regarding the lattcr, wc arc concerncd with "capital services" as an input, in a similar way to thinking of "labour serviccs" as bcing morc meaningful than just the number of cmployces. The capital serviccs will reflect the insurance function that shareholders' funds can provide, and the capital investment that improves the administration, selling and investment. An estimatc of total factor productivity in a (U.S.) proprietary and a (U.S.) mutual is given by Weiss (1986), with both outputs and inputs being assessed in some detail. However, it is more usual in practicc for productivity calculations to be restrictcd to the partial measure of labour productivity.

5.8. Productivity calculations should not, however, be given overstated importance. In particular a proprietary office which is aiming to maximise profits for shareholders would note that productivity and profitability may move in different directions, as mentioned by Corby (1967). In the following circumstances, for example, highcr productivity as measured may be associated with lower profits:

(i) the input mcasure may bc an incomplete indicator of the labour and capital scrvices employed

(ii) the output measure may be incomplete

(iii) there may be changes in the prices of inputs or outputs which are ignored in the real productivity measure but affect profits (if productivity is the objective then profitable high-price services using low-price inputs may be ignored)

(iv) productivity is an average measure but it still may be profitable to expand output at the margin even though the effectiveness of the additional inputs may reduce average productivity

(v) a productivity rise may reflect the changing importance of high- and low-productivity activities in the company but relative profitabilities may be such that overall profits move in an opposite direction

(vi) raising current productivity may conflict with long-term profitability by ignoring the impact on future operations.

5.9. Nevertheless, productivity measures can be a useful operational tool provided that these considerations are borne in mind. The National Board of Prices and Incomes (1968) reported on the introduction of a productivity index at Prudential Assurance which involved the weighting of various functions such as the administration of new and existing policics. Lcvitt (1985) refers to some examples in insurance of companies' planning and budgetting procedures which require assessments of activity levels.

5.10. This paper has shown that considerable effort could be used to prepare a sophisticatcd productivity index for a company. Quite obviously some short cuts are possible. For example a number of generalised activities on the lines of Appendix 1 could be countcd, and weighted by relative expenses for these functions which either arc assessed as applicable to the office or alternatively which are derived from industry analyses of expenscs. This last possibility provides an easy way for a company to measure its output, and hence productivity, provided it recognises the simplifications involved.

5.11. Onc rcason for rcquiring a productivity measure may be the need for an index to which remuneration bonuses are to be related. This clearly raises a number of separate 
issues, including the amount of detail in the productivity index, the incentives which result, and the possible conflicts between productivity and profits.

\section{Expense inflation}

5.12. It is sometimes assumed by actuaries, in profit-testing and projection work, that expenses will increase with salaries (or some other indicator of earnings). It can be said that most of an office's costs will be salaries and hence an earnings index is appropriate; however, this ignores the expectation of productivity improvements which would typically result in expenses rising less than earnings. It is therefore more satisfactory to assume that expenses would increase at the same rate as inflation (i.e. of prices), although there could be offsetting influences such as increasingly complex administration and more services being provided per policy.

\section{Economies of scale}

5.13. Studies of economies of scale in life assurance have already been referred to in para. 2.2. In designing an output measure against which to measure costs, reference can be made to Geehan (1977) who uses an output measure which is a weighted average of activities performed as described in Hirshhorn and Geehan (1977). This is obviously more complicated than an analysis merely relating the expenses/premiums ratio to a number of parameters such as annual and single premiums, though the extra sophistication may be valuable.

\section{Industry output measurement}

5.14. Given the approach to measuring the output of an individual life office, this can be adapted to examine the output of the life assurance industry in the U.K. as a whole. The results are shown in Appendix 6 and imply a $77 \%$ increase in output over the period 198189. The method uses figures for new policies, new business premiums and business in force as given in Association of British Insurers (1990) and previous similar publications. Sponsored pension business and permanent health insurance are not here included. The weights used for ordinary life business are based on those in the inter-office expense investigation described by Luffrum, O'Leary and Shedden (1986). Different weights have been assumed to apply to industrial policies. Note that the business indicators include items of a monetary as well as a real nature, and the weights for the former have been adjusted to deflate for (general) price rises. The significant increases in output in 1983, 1986, 1987 and 1988 are apparent; in other years the increases were rather lower.

5.15. These calculations are of a very rough nature only. The weights assumed are open to debate: for example differences between further sub-divisions of policies could be incorporated. Consideration could also be given to "quality" changes, taking account of the increasing complexity of administration - provided that the additional services are valued by policyholders. No account has been taken of shareholders' profits as part of output in this analysis, nor of the "insurance" function as such. And also note that the results are of gross rather than net output. There are obviously many problems in this simple type of presentation, but it is felt that the results are instructive.

5.I6. The method used in U.K. national income accounting for assessing life assurance industry output is to add aggregate expenses and shareholders' profits, and deflate the result by the consumers' expenditure deflator. The assumption that increases in life assurance 
prices match those generally is therefore quite critical. The methodology in 5.14. reduces the dependance on this assumption by incorporating certain fixed weighting factors, and although it is susceptible to other errors, it is felt it is a sounder base for measurement.

\section{Conclusion}

6.1. It is possible to view output of a life assurance firm, or of the industry, as being the sum of the factor incomes. From this angle one can also see output as equalling consumers' expenditure on life assurance, with a distinction between gross output (including the value of intermediate purchases) and net output. The use of premiums as an output indicator can be misleading as the majority of premium income is a transfer payment within the body of policyholders.

6.2. This approach emphasises output as being the servicing activities involved. These activities may be "handling" in the sense of selling + administration + investment; or they may be "insurance" in terms of shareholders" capital enabling valuable guarantees to be given. We can define these activities more precisely to identify units of output and therefore determine prices for each of the functions involved. Then the changes in current price output can be analysed in terms of the increase in real output and what is a change in price. This process is likely to involve a number of approximations, though the use of homogeneous units of output will help minimise the problems. The analysis of profits in respect of "insurance" functions is likely, however, to remain a difficult area.

6.3. A life office would find it possible to determine an output index on this basis which it could use as part of an indicator of productivity. This may be a valuable tool for managing the company's operations provided that the limitations are recognised and especially the possible conflicts between productivity growth and profit-maximisation.

6.4. Life assurance is long-term business which involves estimates of future conditions and experience to determine profits. There may be reasons for regarding accountability within life assurance as somewhat limited: for example, high expenses may be recouped by effectively reducing transfer payments. In this context a disciplined approach to output measurement and productivity may be valuable for the company management.

6.5. This view of output was also applied to the measurement of economies of scale, the size of the life assurance industry, and financial services taxation. What is important is to recognise the output as reflecting the particular services offered by life assurance. Understanding the industry in this form can benefit those determining public policy and those directly responsible for running life assurance businesses. 


\section{APPENDIX 1}

Functions: selling

administration and

investment in relation to:

\begin{tabular}{ccccc} 
& & Basic & & \\
Quantity & Quality & Service & Price per & \\
& Indicator & Units & BSU (£) & Cost (£) \\
\hline
\end{tabular}

Year 1

New life policies

$10,000 \quad 1$

10,000

110.00

$1,100,000$

New pension policies

$6,000 \quad 1$

6,000

188.33

$1,130,000$

Existing life policies

$80,000 \quad 1$

80,000

10.00

800,000

Existing pension policies

$40,000 \quad 1$

40,000

12.00

$\frac{480,000}{3,510,000}$

Year 2

New life policies

New pension policies

Existing life policies

$11,000 \quad 1$

$8,000 \quad 1.055$

11,000

114.55

$1,260,000$

$83,000 \quad 1.05$

8,440

197.87

$1,670,000$

87,150

10.90

950,000

Existing pension policies

$43,000 \quad 1$

43,000

13.14

565,000

$4,445,000$

Year 2 output at year 1 prices and year 1 quality

New life policies

$\begin{array}{rr}11,000 & 1 \\ 8,000 & 1 \\ 83,000 & 1 \\ 43,000 & 1\end{array}$

11,000

8,000

110.00

$1,210,000$

83,000

188.33

$1,506,640$

Existing life policies

43,000

10.00

830,000

Existing pension policies

12.00

$\frac{516,000}{4,062,640}$

Year 2 output at year 1 prices and year 2 quality

New life policies

$\begin{array}{rl}11,000 & 1 \\ 8,000 & 1.055 \\ 83,000 & 1.05 \\ 43,000 & 1\end{array}$

11,000

110.00

$1,210,000$

New pension policies

8,440

188.33

$1,589,505$

87,150

10.00

871,500

Existing pension policies

43,000

12.00

516,000

$4,187,005$

Year 2 prices for the generalised activities

New life policies

New pension policies

208.75

Existing life policies

11.45

Existing pension policies

13.14 
Functions: acquisition,

administration and

investment in relation to:

\begin{tabular}{ccccc} 
Quantity & Basic & & \\
& $\begin{array}{c}\text { Quality } \\
\text { Indicator }\end{array}$ & Service & Price per & \\
& Units & BSU (£) & Cost(£) \\
\hline
\end{tabular}

Year 1

$\begin{array}{llllll}\text { All policies } & 136,000 & 1 & 136,000 & 25.81 & 3,510,000\end{array}$

$\underline{\text { Year } 2}$

$\begin{array}{llllll}\text { All policies } & 145,000 & 1.119 & 162,224 & 27.40 & 4,445,000\end{array}$

Year 2 output at year 1 prices and year 1 quality
All policies
$145,000 \quad 1$
145,000
25.81
$3,742,450$

Year 2 output at year 1 prices and year 2 quality
All policies
145,000
1.119
162,224
25.81
$4,187,005$ 
APPENDIX 3

Functions :

$\begin{array}{ccclc}\text { Quantity } & \text { Buasic } & & \\ & \text { Quality } & \text { Service } & \text { Price per } & \\ & \text { Indicator } & \text { Units } & \text { BSU (£) } & \text { Cost (£) }\end{array}$

Year 1

\begin{tabular}{lrrrrr}
\hline Sending statements to policyholders & 80,000 & 1 & 80,000 & 2 & 160,000 \\
Dealing with claims & 7,000 & 1 & 7,000 & 30 & 210,000 \\
Dealing with enquiries on renewals & 4,000 & 1 & 4,000 & 5 & 20,000 \\
Dealing with enquiries on surrenders & 5,000 & 1 & 5,000 & 50 & 250,000 \\
Investment service & 80,000 & 1 & 80,000 & 2 & 160,000 \\
& & & & & 800,000
\end{tabular}

Year 2

Sending statements to policyholders

$83,000 \quad 1.02$

84,660

$2.13 \quad 180,000$

Dealing with claims

$7,100 \quad 1$

7,100

30.85

219,000

Dealing with enquiries on renewals

$4,636 \quad 1$

4,636

5.39

25,000

Dealing with enquiries on surrenders

$6,000 \quad 1$

6,000

58.33

350,000

Investment service

$83,000 \quad 1$

83,000

2.12

$\underline{176,000}$

950,000

Year 2 output at year 1 prices and year 2 quality

Sending statements to policyholders $\quad 83,000$

Dealing with claims

7,100

1.02

84,660

2

169,320

Dealing with enquiries on renewals

4,636

7,100

30

213,000

Dealing with enquiries on surrenders

6,000

4,636

23,180

Investment service

83,000

6,000

300,000

83,000

166,000

871,500

Increase in basic service units $=8.94 \%$ 


\section{APPENDIX 4}

\section{Expenses in relation to new pension policies}

$\begin{array}{lrrr} & \text { Cost per } & \text { Current price } \\ \text { Parameter } & \text { Number } & \text { parameter } & \text { cost }\end{array}$

Year 1

New policies

6,000

30.00

180,000

New annual premiums

$3,000,000$

0.30

900,000

New single premiums

$5,000,000$

0.01

50,000

$1,130,000$

Year 2

New policies

8,000

31.50

252,000

New annual premiums

$4,500,000$

0.30

$1,350,000$

New single premiums

$6,698,000$

0.01

66,980

$1,668,980$

\section{NOTES}

(a) Costs in year 1 relate to numbers of new policies and new business premiums, and the average cost per new policy $=1,130,000 / 6,000=188.33$.

(b) In year 2 the expenses are shown as would arise if "per policy" costs increased by $5 \%$, the level of general inflation, and the average cost per new policy $=1,668,980 / 8,000=208.62$, i. e. $10.77 \%$ higher than in (a).

(c) The $10.77 \%$ incrcase in averagc cost includes a $5 \%$ general inflationary uplift and the remainder, i. e. $5.50 \%$ can be regarded as the increase in "size" of policy or a "quality" indicator.

(d) Appendix 1 shows that actual costs in ycar 2 werc 1,670,000. Thcrefore, actual costs per basic service unit increased by slightly morc than the ratc of general inflation. 


\section{APPENDIX 5}

Functions:

\begin{tabular}{|c|c|c|c|c|c|c|}
\hline Quantity & $\begin{array}{l}\text { Quality } \\
\text { Indicator }\end{array}$ & $\begin{array}{c}\text { Basic } \\
\text { Service } \\
\text { Units }\end{array}$ & $\begin{array}{c}\text { Expenses } \\
(£)\end{array}$ & $\begin{array}{l}\text { Profits } \\
\text { (㓞) }\end{array}$ & $\begin{array}{c}\text { Expenses } \\
\text { \& Profit } \\
\text { (ई) }\end{array}$ & $\begin{array}{c}\text { Price } \\
\text { per } \\
B S U(\mathfrak{\xi})\end{array}$ \\
\hline
\end{tabular}

Year 1

Acquisition, administration and investment in relation to:

New life policies

\begin{tabular}{rrrrrrr}
10,000 & 1 & 10,000 & $1,100,000$ & 200,000 & $1,300,000$ & 130.00 \\
6,000 & 1 & 6,000 & $1,130,000$ & 150,000 & $1,280,000$ & 213.33 \\
80,000 & 1 & 80,000 & 800,000 & 40,000 & 840,000 & 20.50 \\
40,000 & 1 & 40,000 & 480,000 & 20,000 & 500,000 & 12.50 \\
& & & & & \\
& & 1,000 & & $1,090,000$ & $1,090,000$ & 1090.00 \\
\cline { 3 - 5 } & & $3,510,000$ & $1,500,000$ & $5,010,000$ &
\end{tabular}

Year 2

Acquisition, administration and investment in relation to:

\begin{tabular}{lrlrrrrr} 
New life policies & 11,000 & 1 & 11,000 & $1,260,000$ & 210,000 & $1,470,000$ & 133.64 \\
New pension policies & 8,000 & 1.055 & 8,440 & $1,670,000$ & 160,000 & $1,830,000$ & 216.82 \\
Existing life policies & 83,000 & 1.05 & 87,150 & 950,000 & 40,000 & 990,000 & 11.36 \\
Existing pension policies & 43,000 & 1 & 43,000 & 565,000 & 20,000 & 585,000 & 13.60 \\
Insurance & & & 1,048 & & $1,200,000$ & $1,200,000$ & 1144.50 \\
\cline { 4 - 6 } & & & & $4,445,000$ & $1,630,000$ & $6,075,000$ &
\end{tabular}

Year 2 output at year prices and year 2 quality

Acquisition, administration and investment in relation to:

New life policies

New pension policies

Existing life policies

Existing pension policies

1nsurance

$\begin{array}{rlr}11,000 & 1 & 11,000 \\ 8,000 & 1.055 & 8,440 \\ 83,000 & 1.05 & 87,150 \\ 43,000 & 1 & 43,000\end{array}$

1,048

$$
\begin{array}{rr}
1,430,000 & 130.00 \\
1,800,533 & 213.33 \\
915,075 & 10.50 \\
537,500 & 12.50 \\
& \\
1,142,857 & 1090.00 \\
\hline 5,825,965 &
\end{array}
$$

$(16.3 \%$ increase $)$ 


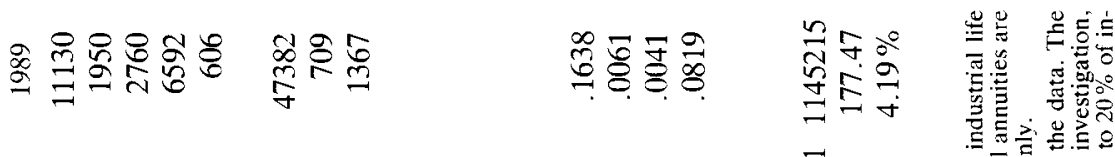

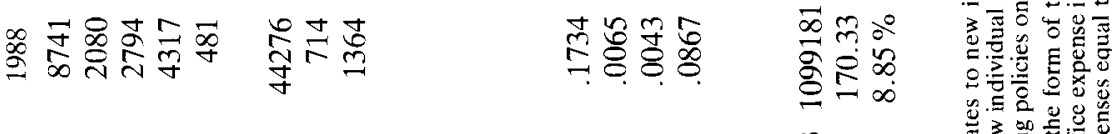

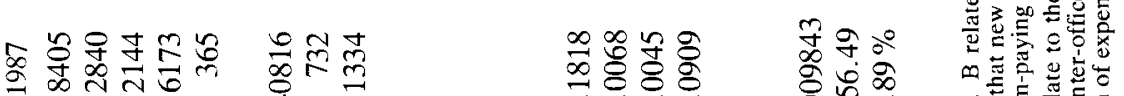

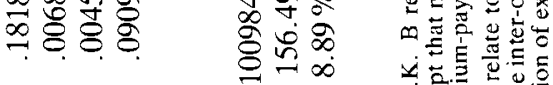

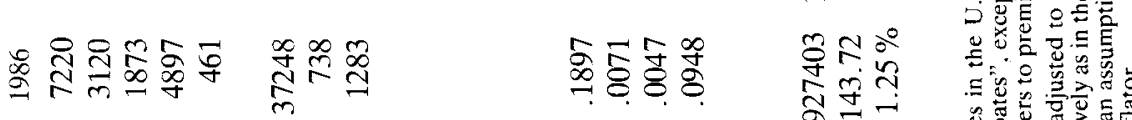

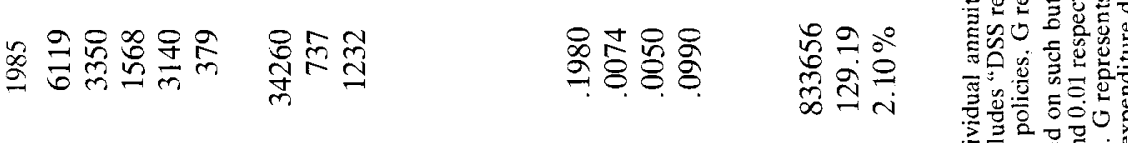

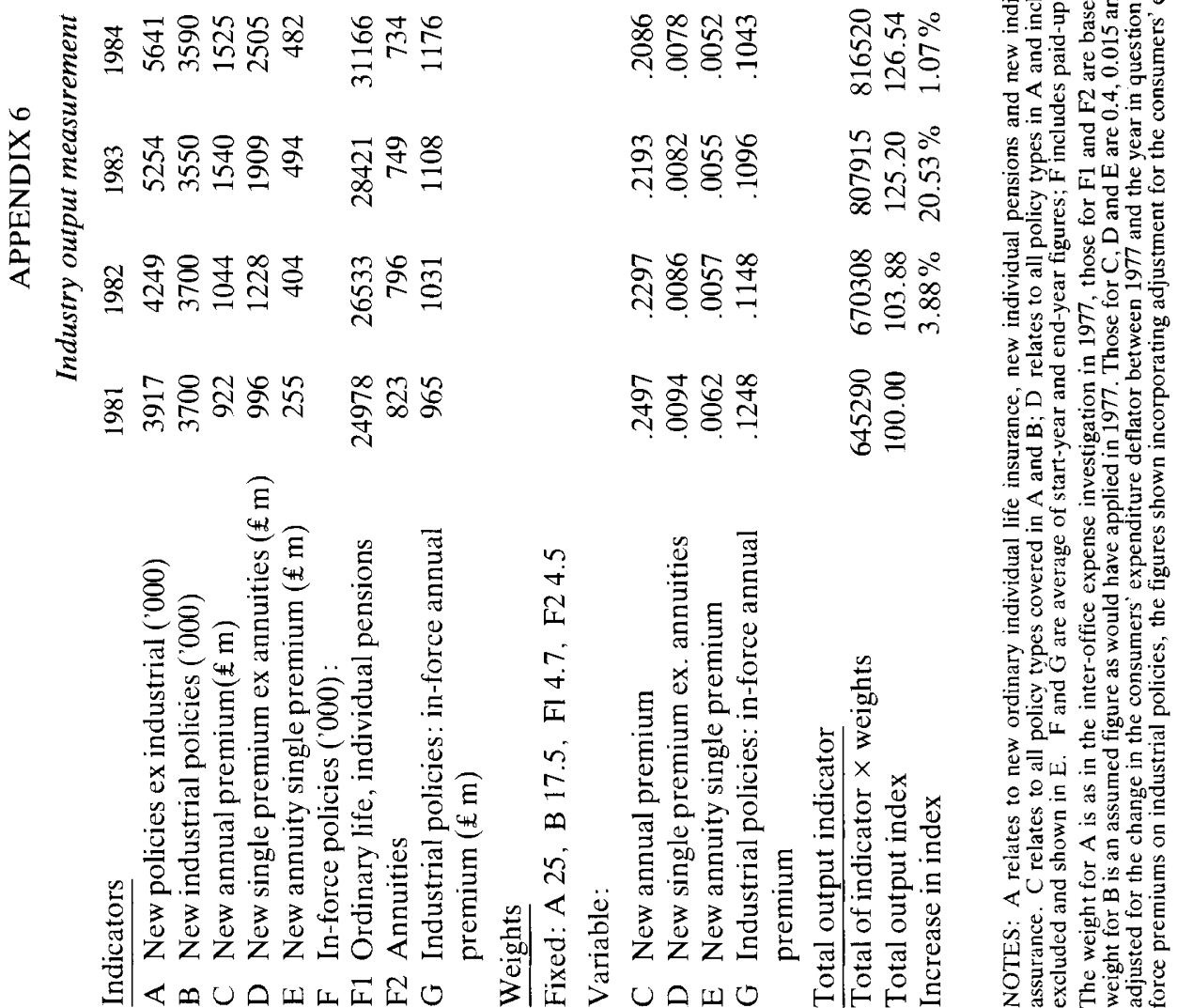




\section{REFERENCES}

Association of British Insurers (1990), "Insurance Statistics 1985-1989", Association of British Insurers, London.

BARRAS, R. and SWANN, J. (1983), "The Adoption and Impact of Information Technology in the U. K. Insurance Industry", Technical Change Centre, London.

BURGESS, J. and WALKER, G. (1982), "Returns to Scale in the Australian Life Insurance Industry: A Comment", The Economic Record, vol. 58.

BURROWS, R. P. and WHITEHEAD, G. H. (1987), "The Determination of Life Office Appraisal Values", Journal of the Institute of Actuaries, vol. 114.

Central Statistical Office (1985), "United Kingdom National Accounts. Sources and Methods", H.M.S. O., London.

COLENUTT, D. W. (1977a), "Determinants of Expense Ratios in United Kingdom Life Assurers", Journal of Risk and Insurance, vol. 44.

COLENUTT, D. W. (1977b), "Economies of scale in the United Kingdom ordinary life assurance industry", Applied Economics, vol. 9.

CORBY, F. B. (1967), "Some Aspects of Life Office Administration", Journal of the Institute of Actuaries Students' Society, vol. 18.

DENISON, E. F. (1967), "Why Growth Rates Differ. Postwar Experience in Nine Western Countries", Brookings Institution, Washington.

DIACON, S. R. (1981), "Scale Economies in Life Insurance", Papers in Risk and Insurance: Papers Presented to the Third Meeting of U.K. Insurance Economists, Department of Industrial Economics, Nottingham University.

EARLE, J. W. P. (1972), "The Capital Requirements of a New Life Office", presented to the Institute of Actuaries Students' Society.

ELVEN, R. (1964), "The Trend in the Expenses of a Life Office", Transactions of the 17th International Congress of Actuaries, vol. 2.

FINSINGER, J., HAMMOND, E. and TAPP, J. (1985), "Insurance: Competition or Regulation?", The Institute for Fiscal Studies, London.

FRANKLIN, P. J. and WOODHEAD, C. (1980), "The UK Life Assurance Industry", Croom Helm, London.

GEEHAN, R. (1977), "Returns to scale in the life insurance industry", Bell Journal of Economics, vol. 8.

GERSHUNY, J. I. and MILES, I. D. (1983), "The New Service Economy. The Transformation of Employment in Industrial Societies", Frances Pinter, London.

HIRSHHORN, R. and GEEHAN, R. (1977), "Measuring the Real Output of the Life Insurance Industry", Review of Economics and Statistics, vol. 49.

HOUSTON, D. B. and SIMON, R. M. (1970), "Economies of Scale in Financial Institutions: a Study in Life Insurance", Econometrica, vol. 38.

JOHNSTON, J. and MURPHY, G. W. (1957), "The Growth of Life Assurance in the U. K. since $1880^{\circ}$, Transactions of the Manchester Statistical Society.

KNIGHT, F. C. (1964), "Insurance productivity", Journal of the Chartered Insurance Institute, vol. 61.

LEE, R. (1985), "A Prophet of Profits: An Introduction to the theory and application of profit tests", Journal of the Institute of Actuaries Students' Society, vol. 28.

LEVITT, M. S. (1985), "Productivity in Central Government", Public Finance Foundation, London.

LEWIS, S. (ed.) (1986), "Output and Performance Measurement in Central Government: Progress in Departments", HM Treasury, London.

LUFFRUM, G. G., O'LEARY, A. G. and SHEDDEN, A.D. (1986), "The Life Associations' InterOffice Expense Investigation", Journal of the Institute of Actuaries, vol. 113. 
MARSHALL, J. M. (1974a), "Insurance as a market in contingent claims: structure and performance", Bell Journal of Economics and Management Science, vol. 5.

MARSHALL, J. M. (1974b), "Insurance Theory: Reserves Versus Mutuality", Economic Inquiry, vol. 12.

MINTO, G. (1989), "On the Definition and Measurement of Life Assurance Output", Papers in Risk and Insurance: Papers presented to the Eleventh Meeting of U. K. Insurance Economists, Department of Industrial Economics, Nottingham University.

National Board of Prices and Incomes (1968), "Agreements Relating to Terms and Conditions of Employment of Staff Employed by the Prudential Assurance Company Ltd. and the Pearl Assurance Company Ltd.", H. M. S. O., London.

PRAETZ, P. D. (1981), "Returns to Scale in the Australian Life Insurance Industry", The Economic Record, vol. 57.

PRAETZ, P. D. (1983), "The effect of size and other economic factors on the Expense Rate Behaviour of U. K. Life Insurance Companies", Journal of the Institute of Actuaries", vol. 110.

PRAETZ, P. D. (1984), "The Effect of Size and Other Factors on the Cost Behaviour of Insurance Companies: Some International Evidence", Transactions of the Twenty-Second International Congress of Actuaries, vol. 3.

RAJAN, A. (1985), "New Technology and Employment in Insurance, Banking and Building Societies: Recent Experience and Future Impact", Gower, Aldershot.

SMART, I. C. (1977), "Pricing and Profitability in a Life Office", Journal of the Institute of Actuaries, vol. 104.

WEISS, M. A. (1986), "Analysis of Productivity at the Firm Level: An Application to Life Insurers", Journal of Risk and Insurance, vol. 53. 